\title{
One Giant Leap for Family Medicine: Preparing the 21st-Century Physician to Practice Patient-Centered, High-Performance Family Medicine
}

\author{
Perry A. Pugno, MD, MPH
}

In my present position as Director of the Medical Education Division for the American Academy of Family Physicians, I spend the majority of my time collecting and sharing information about family medicine graduate education or facilitating communication among our many constituencies and affiliated organizations. In general, my personal biases regarding the direction that family medicine education should take are subjugated to representing current policies, requirements, and official recommendations. This is a unique and welcome opportunity for me to share my personal vision of how I wish family medicine education would evolve. However, I must emphasize from the very beginning that this vision is "firmly cast in Jell-O." I readily admit that my opinions evolve as I watch the health care environment and the practice of medicine change over time. Nevertheless, there are enduring themes about which I am increasingly confident. I must also admit that, as the reality of aging becomes increasingly apparent to me, I'm inclined to see myself less as a health care provider and more as a consumer of those services; so, the viewpoint of how I want my doctor to function and relate to me in the future is also evolving. With all of these biases and caveats laid out, let me begin by describing the naissance of my current vision for the future of family medicine education.

The primary values evolving in family medicine focus on both the wants and the needs of patients. In my opinion, family medicine as a discipline has always been patient centered, and it makes perfect

From the Division of Medical Education, American Academy of Family Physicians, Leawood, Kansas.

Funding: none.

Conflict of interest: none declared.

Previous presentation: Presented at the $40^{\text {th }}$ Anniversary Symposium of the American Board of Family Medicine, October 24, 2009, Lexington, KY.

Corresponding author: Perry A. Pugno, MD, MPH, Division of Medical Education, American Academy of Family Physicians, 11400 Tomahawk Creek Parkway, Leawood, KS 66211 (E-mail: ppugno@aafp.org). sense to me that our educational framework should be similarly prioritized. But many forces influence the practice of medicine, and I believe that those forces ultimately must change the training of physicians if they are to practice in that future environment. Those trends include such familiar topics as the aging of the US population and shifting generational priorities. They include the outcomes from the Future of Family Medicine project-including the revalidation by family physicians of both hospital and maternity care-and both the current reality and evolving ecology of health care. ${ }^{1,2}$ It is clear, for example, that medical education needs to migrate from a hospital-centric to an ambulatory care-focused system.

During recent years, interest has grown in new training models such as competency-based education. Policy makers are fostering a culture of patient safety and quality improvement. They are beginning to embrace the patient-centered medical home as the ideal model for ambulatory practice. Certainly during the last 2 years the nation's economic developments have helped focus the public's and the legislature's attention on our currently dysfunctional health care system. Economic concerns have increased the realization that we must move toward a primary care-based health system that will decrease costs and improve outcomes. During the next 10 years I think these dynamics will not fade but will continue to escalate and become even stronger drivers of change.

\section{Internal Drivers of Change}

We have seen a persistent trend of reductionism in medicine during the past 50 years. Specialization has now not only parsed patient populations by age, sex, and organ system but also by environment of care. We've watched the rapid development of emergency medicine, hospitalists, intensivists, "laborists, " "procedureists," and other department"ists" of increasingly narrow specialization. The 
recent report by the Institute of Medicine recommending further reductions in residency training duty hours further serves to narrow what can and is being taught to the physicians of tomorrow. ${ }^{3}$ The favorable trend toward practicing evidence-based medicine has revealed a "dark side" through the indiscriminate application of idealized clinical pathways that seem to validate the aphorism "one size fits nobody." Residency training directors are beginning to recognize that today's medical school graduates lack the clinical patient assessment skills of their predecessors.

\section{External Trends}

Since the publication of the Institute of Medicine reports "To Err is Human" and "Crossing the Quality Chasm," the public no longer assumes that the health care they are receiving today assures them quality and safety. ${ }^{4,5}$ The nation's economic challenges have limited the access to health care for a growing segment of the population, and it has motivated the remaining population to struggle with the dichotomy of getting maximal benefit for their health care dollar versus believing that everyone deserves to benefit from the maximal resources of today's health technology in every case. These economic pressures have also had a dual impact on medical education. Not only is student educational debt escalating, it has also precipitated multiple initiatives to shorten medical school time requirements, potentially further limiting the clinical skills in which new medical school graduates are proficient. ${ }^{6}$ Finally, lifestyle priorities and expectations of income are driving medical students' career decisions, and training environments that offer greater control over the content of postgraduate education are attracting resident physicians. ${ }^{7}$ The Family Medicine P4 project has reinforced prior observations that today's medical students are willing to exchange longer training periods for content choice and a perception of value-added for extended training. 8 ,

\section{What's Really Important}

All of these environmental drivers must be viewed within the context of 3 questions: (1) What do patients want? (2) What do patients need? and (3) What does this nation need from its health care system and providers?
Multiple studies, including the Future of Family Medicine project, have validated that patients want a personal physician. ${ }^{1}$ They want greater access and attention from a professional who gets to know them and their individual desires and who can help them navigate our increasingly complex health care system. They also want access options, even selecting asynchronous contact when personal contact isn't convenient. They want a provider who can use technology when it's appropriate, and they want cost-sensitivity and the option to make their own decisions in a "high-touch" environment.

What patients want must be balanced with what we as physicians know that they need. $\mathrm{Pa}$ tients clearly need individualized care because few have a single major illness without comorbidities. They need a system that focuses on prevention and the capacity to provide care according to "what is best for this individual at this time and in this situation."

As a nation we are beginning to understand that our current expensive, specialty-focused, and uncoordinated health care system is simply not sustainable. The nation needs truly generalist physicians who have historically been proven to be the most effective at meeting population needs when resources are scarce. The recent experience in the Commonwealth of Massachusetts, the state with the highest ratio of primary care providers to population, clearly demonstrated that universal access will undoubtedly result in demands for primary care access that cannot be met with our current health care workforce. The burden of illness and disability in our nation is proof positive that we need more primary care physicians who can provide health promotion and disease prevention. The aging of the US population demands that the provider of tomorrow is skilled in the management of chronic disease and the optimal care for the limitations of aging. Our geographic maldistribution of resources demands improved patient access to physicians who, although focused on providing primarily ambulatory care, can also meet local needs for maternity and hospital care. And, finally, the patient-centered medical home model demands a generalist provider who can both lead and manage multidisciplinary teams to address the needs and wants of a diverse population. 


\section{A New Family Physician Educational Model}

As a consequence of all these factors, drivers, and trends, it is my belief that the postgraduate education of family physicians must change. That change must be built around 3 key elements: (1) a 4-year residency training period; (2) a longitudinal educational experience in continuity of care with a patient population based in a community practice setting; and (3) the capacity for trainees to customize their residency experience by selecting a "valueadded" component to their training.

To prepare the family physician of tomorrow for practice in a patient-centered, high-performance health care system, I believe that the residency period must be a 4-year postgraduate training curriculum. The educational framework must be designed around 4 years of training with advancement based on the achievement of well-defined competency milestones. Such a structure could allow for the potential completion of all requirements within a shorter period of time.

I believe that our educational focus must evolve from "a practice within a training program" to "a training program within a practice" model. In other words, resident physicians must continue to be trained in an environment that emphasizes the care of a continuity patient population. But the training concept originated in 1969 was that residents would experience continuity practice in a "model family practice unit." The reality seen during the past 30 years is that few of our current residency family medicine centers are indeed "models" of how practice should be conducted. We must move the experience that is unique to our discipline into stable, community practices of family physicians exhibiting the best examples of the patient-centered medical home model.

Finally, it is clear to experienced educators that today's trainees want choice and the capacity to mold their educational program along the lines of personal interests and priorities. Early studies about extending the training of family physicians demonstrated that a growing population of medical students would favor a lengthening of the residency period if it also offered the option of customizing their experience to meet personal interests. ${ }^{10} \mathrm{Up}$ to $25 \%$ of today's family medicine residency graduates are already seeking additional training in the form of fellowships and other academic programs. ${ }^{11}$ The Association of Family Medicine Res- idency Directors has put forth guidelines for the inclusion of "Areas of Concentration" during family medicine residency training, ${ }^{12}$ and the $\mathrm{P} 4$ Project has included multiple examples of highly functional and innovative residency training profiles that allow for a customized training experience. ${ }^{13}$ To support these 3 training elements, I propose a future family medicine residency curriculum that includes the following curriculum components.

\section{First-Year Curriculum}

The priority of the first-year curriculum would be to establish and solidify the basic clinical skills in the new medical school graduate. As the providers of first contact, family physicians must be diagnosticians of the first order. They must have the emotional intelligence and communication skills to efficiently gather historical information in an environment of growing trust between patient and physician. Family physicians must also develop advanced physical diagnostic skills that are independent of technology, and they must be capable of using technology to validate their diagnostic assessments, thereby increasing both quality and patient safety while controlling costs. The first year of training must provide an opportunity for the new physician to see the extremes of illness and to learn to care for sick people. This will teach them what to look for in the ambulatory setting and how to optimize their decision-making skills when hospitalization is considered. My personal bias is that family physicians need at least some first-hand participatory experience in major surgical procedures. The benefits of doing so go well beyond that of simply learning sterile technique, reviewing anatomy, and developing basic "cutting and sewing" skills. Many of my former residents have heard me say, "If you've never had your hands on the inside, how confident are you of what you are feeling from the outside?" In other words, I believe that surgical experience also substantially enhances the skills of physical diagnosis.

The first-year curriculum also would be the time to begin a continuity ambulatory practice with at least 3 patient care sessions per week, even if they are only 1 to 2 hours in length. This is the opportunity for new residents to establish their ambulatory care skills and their family medicine identity while they maximize the opportunity for learning the benefits of longitudinal patient care. Priorities 
for the first-year curriculum also would include learning basic manual skills, such as procedural skills development, as well as becoming confident at delivering life-saving and patient-stabilization skills. Generalist physicians need the intellectual honesty to know when they need help and the patient-management skills to buy them sufficient time to get it.

To cope with the fact that residents cannot be in their continuity practices all the time, and to support the concept of the health care team within the patient-centered medical home, all residents would be part of a "training team" that will include a resident at each level of training (years 1 through 4), at least one family physician faculty mentor, and at least one other provider member, such as a nurse practitioner or physician assistant. Although each patient will have his or her own primary provider, the team will share responsibility for the continuity patient population. Continuity of care for each patient in whatever setting that are in will be a firstorder priority for both the individual resident and the training team.

\section{Second-Year Curriculum}

The second-year curriculum is the time when the philosophic underpinnings of family medicine and its values would be reinforced. A core curriculum designed to support advanced inpatient skills and ambulatory skill development should be built around target competencies for each experience. Residents would be exposed to the outpatient components of subspecialty care and build on the initial procedural competencies they began during the first year of training. Experiences in medical and surgical subspecialties would be augmented by curriculum focused on emergency medicine, critical care, prenatal care, and ambulatory gynecology. The second year would also begin an expansion of residents' continuity practice to $25 \%$ of the resident's time being spent in daily family medicine practice hours.

\section{Third-Year Curriculum}

The third-year curriculum will complete the core requirements while bringing forward an emphasis on preventive care, public health, community medicine, quality improvement, and chronic care management. The $25 \%$ continuity practice would continue, but electives during this year would allow the individual resident to pursue individual interests and leverage clinical areas of concentration in anticipation of their target practices. Options during this year include increased emphasis in preventive medicine and public health, maternal child care, endoscopy and procedural medicine, geriatrics, sports medicine, and hospitalist skill development. The third year also will be the time when residents begin curriculum designed to develop leadership skills, team management skills, and systems-based care.

\section{Fourth-Year Curriculum}

The fourth-year will consist of a 50\% continuity practice and the opportunity for extensive customization of the individual resident's curriculum. For some this will be an opportunity to gather further experience in their areas of concentration, but all residents would also have the expectation of gaining supervised experience in teaching and mentoring junior residents. The fourth year also would be the time when residents are required to complete a scholarly project. It could be either longitudinal or focused but will emphasize the skills of critical assessment of the medical literature, practice improvement, and, for some, even the opportunity to pursue an academic degree if desired. This fourth year will also find a receptive audience for a robust practice management curriculum to include an orientation to health policy and basic training in personal and small business economics.

\section{The Vision for Education}

My vision for all 4 years of training includes welldeveloped milestones for advancement and regular competency testing, including an assessment of not only knowledge and skills, but also the affirmative use of Objective Structured Clinical Examinations, videotaped encounters, and simulation for both training and testing. Residents must have meaningful inpatient responsibilities during all 4 years of training to assure at graduation a level of proficiency sufficient to qualify for independent hospital privileges. Although many residency graduates will be competent to provide full-scope maternity care, everyone who completes a family medicine residency must be capable of conducting a safe, uncomplicated vaginal delivery when called on to do so. Careful monitoring of resident experiences must be conducted through the use of electronic logs, regular review of a personalized educational 
plan, and both the development of and completion of a personal educational portfolio.

The family medicine residency of tomorrow will need a significant expansion of resources to accomplish this educational vision. I believe the original concept of the teaching family medicine model unit is, indeed, the key differentiating factor for family medicine training. This concept truly prepares the residency graduate for the practice environment. Consequently, residencies must operate on the patient-centered medical home model as its clinical practice. Residencies must have robust electronic health records and sufficient administrative support and information management to document the favorable economic impact they have on their institutional sponsors.

The educational demands on the practice will require that the residency has the resources to support simulation technology and detailed information management of educational content. This will require a faculty-to-resident ratio of at least 1:4 with sufficient support staff to meet faculty needs and a structured environment for longitudinal faculty development. The requirement of a scholarly project will demand each residency program to have the time, expertise, and financial resources to support at least a limited research enterprise that will model scholarly productivity by both residents and faculty. All of these changes will demand the strong leadership capabilities of an experienced and well-trained residency program director and an organizational infrastructure to support that individual's continuous skill development.

\section{Conclusion}

These proposed changes represent my personal vision for family medicine education in the future. Is it achievable? Yes. But it will require diligence and determination among the current leadership of our discipline, both within and outside the academic community, to be achieved. However, if family medicine wants to "deliver" on the promise to the American people of a true primary care-based health care system that assures quality, safety, and maximal cost-effectiveness, I believe this is the direction we must go and the investment we must make. Time will tell if we have the will, courage, fortitude, diligence, and support to achieve this vision.

\section{References}

1. Martin JC, Avant RF, Bowman MA, et al. The Future of Family Medicine: a collaborative project of the family medicine community. Ann Fam Med 2004;2(Suppl 1):S3-32.

2. Green LA, Fryer GE Jr, Yawn BP, Lanier D, Dovey SM. The ecology of medical care revisited. N Engl J Med 2001;344:2021-5.

3. Institute of Medicine. Resident duty hours: enhancing sleep, supervision, and safety. Washington, D.C.: The National Academies Press; 2008.

4. Institute of Medicine. To err is human: building a safer health system. Washington, D.C.: The National Academies Press; 2000.

5. IOM (Institute of Medicine). Crossing the quality chasm: a new health system for the $21^{\text {st }}$ century. Washington, D.C.: The National Academies Press; 2000.

6. Harvard Medical School, Department of Continuing Education. Harvard Macy Institute Program for Leading Innovations in Health Care and Education. 2009. Available at http://cme.med.harvard.edu/ index.asp? SECTION $=$ CLASSES $\&$ ID $=00302116 \&$ $\mathrm{SO}=\mathrm{N}$. Accessed 5 October 2009.

7. Pugno PA, McGaha AL, Schmittling GT, DeVilbiss AD, Ostergaard DO. Results of the 2009 National Resident Matching Program. Fam Med 2009;41:56777.

8. TransforMed. Preparing the Personal Physician for Practice $\left(\mathrm{P}^{4}\right)$ Project. Available at http:// www.transformed.com/p4-learnings.cfm. Accessed 5 October 2009.

9. Duane M, Dovey SM, Klein LS, Green LA. Follow-up on family practice residents: perspectives on length and content of training. J Am Board Fam Pract 2004;17:377-83.

10. Lebensohn P, Campos-Outcalt D, Senf J, Pugno PA. Experience with an optional 4-year residency: the University of Arizona Family Medicine Residency. Fam Med 2007;39:488-94.

11. American Academy of Family Physicians. Report on survey of 2009 graduating family medicine residents. Leawood (KS): American Academy of Family Physicians; 2009.

12. Association of Family Medicine Residency Directors. AFMRD guidelines for individual areas of concentration. 2009. Available at http://www.afmrd.org/ files/public/AOC_Individual_Guidelines.pdf. Accessed 25 January 2010.

13. TranforMed. Preparing the Personal Physician for Practice $\left(\mathrm{P}^{4}\right)$ Project [homepage.] Available at http:// www.transformed.com/p4.cfm. Accessed 5 October 2009. 